\title{
La Iglesia parroquial de San Miguel de Llumes
}

\author{
Herbert GonZÁLEZ ZyMLA \\ Departamento de Historia del Arte I (Medieval) UCM.
}

\begin{abstract}
RESUMEN
Alfonso I de Aragón conquistó la taifa de Zaragoza entre los años 1118 y 1120. El fuero de Calatayud, datado en 1131, cita ya la iglesia parroquial de Llumes formando parte de los límites jurisdiccionales de la comunidad de Calatayud. Llumes debe su nombre a la corrupción del término flumes, que significa río. Su iglesia parroquial es un ejemplo interesante del románico zaragozano. Debió construirse en la segunda mitad del siglo XII o en los primeros años del XIII de acuerdo a planta de una sola nave, con ábside semicircular al interior y al exterior, totalmente abovedado (medio cañón sobre fajones y bóveda de horno). Tiene escultura monumental en la portada (tímpano con pantócrator, tetramorfos y Crismón trinitario) y en el arco de triunfo (capiteles de la huída a Egipto y San Miguel). El 27 de julio de 1258 el obispo de Tarazona, García Fortín, donó la parroquia de Llumes al abad Pedro Serrano y al Monasterio de Piedra con sus diezmos, primicias y emolumentos (excepto el derecho de visita) a condición de que el monasterio proveyese de vicario a la parroquia y se cantase una misa, el día de San Miguel, en memoria del alma del obispo. En 1642 los monjes de Piedra perdieron el derecho a nombrar al vicario de Llumes, pero no la propiedad de la iglesia y sus rentas, que mantuvieron hasta la desamortización.
\end{abstract}

Palabras clave: Iglesia parroquial de San Miguel de Llumes, Monasterio de Piedra, Cister, Crismón trinitario, Pedro Serrano, García Fortín.

\section{St. Michael of Llumes' parish church}

\begin{abstract}
Alfonso I de Aragón conquered the taifa (Moorish kingdom) of Zaragoza between 1118 and 1120. The jurisdiction of Calatayud, dated 1131, already cites the parish church of Llumes making the jurisdictional limits of the community of Calatayud. Llumes owns its name to the corruption of the term flumes, which means river. Its parish church is an interesting example of Zaragoza's Romanesque art. It must have been built either at the second half of the 12th century or at the beginning of the 13th, according to its only nave on a single story, with semicircular apse to both the interior and the exterior, fully vaulted (half a barrel over transverse arches and an oven vault). It counts on monumental sculptures both on the facade (tympanum with pantocrator, tetramorphs and trinitary Chi-Rho) and on the triumphal arch (capitals of the escape to Egypt and St. Michael). On July 27th 1258 the Bishop of Tarazona, García Fortín, donated the parish of Llumes both to the abbot, Pedro Serrano and the Monasterio de Piedra including its tithes, dues and taxes (except for the right of visit) on condition that the monastery provided the parish with a vicar. In addition, mass had to be sung on St. Michael's day to the memory of the bishop's soul. In 1642 Piedra's monks lost their right to appoint the vicar of Llumes but not the property of the church and its incomes, which they retained until the Disentailment Act.
\end{abstract}

Keywords: San Miguel de Llumes' parish church (St. Michael of Llumes' parish church), Monasterio de Piedra (Stone Monastery), Císter, trinitary Chi-Rho, Pedro Serrano, García Fortín. 
La conquista de la Taifa de Zaragoza fue cuidadosamente preparada por Alfonso I el Batallador, que contó con el apoyo y beneplácito de la iglesia aragonesa, navarra, catalana y de allende los Pirineos, quienes, en 1118, durante el Concilio de Tolouse, dotaron a esta campaña militar con el carácter y beneficios espirituales de una Santa Cruzada contra el Islam ${ }^{1}$. En julio de 1117 Alfonso I, imbuido del espíritu cruzado, empezó a tantear el terreno para someter Zaragoza a un asedio con la ayuda de Gascón III, IX vizconde de Bearne, y de Céntulo IV de Bigorra. Reunió en Ayerbe un formidable ejército que, en su camino hacia Zaragoza, tomó Almudévar, Sariñán, Salcey, Robles y Zuera. El asedio para conquistar Zaragoza comenzó el 22 de mayo de 1118 y concluyó el 19 de diciembre del mismo año con la entrada triunfal del Rey. En realidad, la conquista de Zaragoza y la derrota de la dinastía que la había gobernado durante el siglo XI, los Banu Hud, equivalía al control efectivo sobre la totalidad del territorio que conformaba la Taifa ${ }^{2}$, como se demostró posteriormente con las sucesivas tomas de Tudela, el 22 de febrero de 1119 y Tarazona, cuya sede episcopal fue restaurada inmediatamente y en cuyo territorio eclesiástico está emplazado Llumes. Tras la victoria cristiana en la batalla de Cutanda, en 1120, la frontera quedó fijada en Singra anunciando la futura expansión aragonesa hacia Teruel. A medida que el Rey conquistaba los territorios de la Taifa, les iba otorgando fueros repobladores. Calatayud fue arrebatada a Ramiro I por Alfonso VII de Castilla y le fue devuelta a la corona aragonesa en 1158, por lo que su fijación territorial y repoblación fueron un tanto tardías. El primer fuero de Calatayud fue otorgado en 1120 y revisado en $1131^{3}$. En él se concedían grandes franquicias que hicieron de la ciudad cabeza de una comunidad que perduró hasta 1835.

Llumes fue una de tantas aldeas repobladas tras 1118. Formó parte de la comunidad de Calatayud. En los documentos está citado de dos modos distintos: Flumes y Llumes. La segunda forma es un aragonismo lingüístico romance a partir del término latino Flumen, que significa río o corriente de agua, Flumes vendría a significar Rios, entendiendo la derivación del término como un incorrecto y corrupto uso latino del sustantivo flumen-flumines. Este topónimo hace alusión al río Piedra que nace en el término municipal de Cimballa, a unos 4 kilómetros de Llumes, en un lugar que se denomina los ojos del río Piedra. Llumes es la primera llanura fértil que tiene este curso fluvial. En primavera el río se desborda e inunda durante unas 3 o 4 semanas la llanura. El suelo queda empapado, el río durante unas semanas no

1 IRADIEL, Paulino, MORETA, Salustiano y SARASA, Esteban, Historia Medieval de la España Cristiana, Madrid, Cátedra, 1989, pp. 284-285.

2 CHEJNE, Anwar G., Historia de la España Musulmana, Madrid, 1980, traducción de Pilar Vila, pp. 63-64 y p. 85; VIGUERA MOLINS, María José, El Islam en Aragón, Zaragoza, 1995.

3 ALGORA HERNANDO, Jesús Ignacio y ARRANZ SACRISTÁN, Felicísimo, Fuero de Calatayud, Imprenta y fundición M. Tello, Zaragoza, 1982; FUENTE, Vicente de la, Estudio crítico sobre la historia del derecho en Aragón, Madrid, 1880-1929, Tres volúmenes integrados dentro de la colección titulada: Colección de escritores castellanos, t. XXI, XXXIV y XLII, 1880, t. I, pp. 113-123-140. 
tiene un cauce claro, sino multitud de regueros. Las aguas carbonatadas fertilizan el suelo arcilloso y calizo en medio de los páramos pedregosos y pelados. Estas condiciones agrícolas debieron atraer a los primeros pobladores de Llumes. Sin embargo, las dificultades derivadas de poblar una zona de escorrentía y el frío en los páramos montañosos debieron ser un contratiempo importante para el crecimiento de esta población que ya existía como tal a mediados del siglo XII. Los documentos más antiguos sobre Llumes son aquellos que tienen que ver con el nombramiento del vicario que atendía la parroquia.

En el Lumen Domus Petrae consta que el Monasterio de Piedra, que había sido fundado en 1195 y consagrado en $1218^{4}$, gozaba del pleno patronato de la vicaría de Llumes desde que García Fortín, obispo de Tarazona, con aprobación y consentimiento del Arcediano de Calatayud, Martín de Pedro, del Deán de Calatayud, Fortunio de Verruga, de Sancho de Pedro, sacristán, Gonzalo de Pedro, cantor, y de los Canónigos y Cabido de Tarazona, hicieron donación al Monasterio de Piedra de la iglesia del lugar de Llumes, firmando un acta fechada en Tarazona, a 6 días de las calendas de agosto de 1258, que es el 27 de julio, ante el escribano público del episcopado, Pedro de Bornau. La donación incluía los diezmos, primicias y emolumentos de Llumes, así como su vicaría, que estaba vacante por la renuncia de García Juan, canónigo de Tarazona que hasta entonces había sido su capellán ${ }^{5}$. El obispo se reservó únicamente, para sí y para sus sucesores, el derecho de "visitarla y el de instituir o dar la colación al vicario o capellán que por tiempo sirviere el curato de dicha iglesia". El abad Pedro a quien se cita en el documento es el XII abad de Piedra, Pedro Serrano, que lo fue entre 1253 y 1258. En gratitud por la concesión del pleno dominio de las décimas y vicaría de Llumes, Piedra tenía la obligación de cantar una misa a favor del alma del obispo García Fortín, que se rezaba el día de San Miguel y se comprometió a mantener con esta renta el aceite

4 GONZÁLEZ ZYMLA, Herbert, "Sobre los posibles orígenes del Real Monasterio de Santa María de Piedra: precisiones acerca de su primera ubicación y sentido de su advocación mariana", en Anales de Historia del Arte de la Universidad Complutense de Madrid, n 13, Madrid, 2003, pp. 27-82.

A. H. N. [Archivo Histórico Nacional], Lumen Domus Petrae, Cód. 55-B, fol. 1281 y 1487.

6 La donación recoge lo siguiente: "Cum ea que geruntur in tempore, in oblivione facili prolabantur, nisi scripturae testimonio fulciantur; id circo noverint universi, tam praesentes quam posteri. Quod Nos, García, miseratione Divina tirasonensis episcopus provide ingiter contemplantes, quam pium sunt ac laudabile religiosis viris monasteriis, ac aliis piis locis misericorditer subvenire, in remedium animae nostra, et predecesorum nostrorum, de assensu et voluntate Benerabilium virorum domini Fortunii de Verruga, deani, domini Martín Petri archidiaconi calataiubii, domini Sanchii Petri sacrista, Domini Gundisalvi Petri, cantoris, et capituli canonicorum tirasonensis ecclesiae: Pro nobis, et sucesoribus nostris, damus, concedimus et asignamus, Domino Deo, et Beatae Maria, et vobis, dilecto nostro frati Pedro Abbati, et conventui Monasterii de Petra, vestrisque succesoribus et ipsi Monasterio in perpetuum Ecclesiam de Flumes, per renunciationem García Joannis, canonici et capellan nostri vacantem, cum decimis, primiciis, oblationibus, et ipsius iuribus universis habitis et habendis procuratione ratione visitationis debita, ac institutione vicarii, seu capellan, nobis, et sucesoribus nostris in ea tantum modo reserbatis. Ita videlicet, quod ab hac die quo presens conficitur instrumentum, ipsam ecclesiam habeatis, teneatis, posideatis pacifice, ac potenter vos et Monasterium vestrum perpetuo, sine contradictione, diminutione, et revocatione nostri, nostrumque in posterum succesorum”. A. H. N., Clero, Piedra, carp. 3673, doc. 9. Lumen Domus Petrae, Cód. 55-B, fol. 1282. 
de la lámpara votiva dedicada a la imagen de Santa María de Piedra que presidía el altar mayor de la iglesia abacial". "El abad y convento [...] aceptaron la dicha donación y prometieron que en lo venidero harían oración o conmemoración cada día, por el dicho obispo. Y que ante el altar de la Virgen de Piedra ardería siempre una lámpara en sufragio del dicho obispo. Y que en el día de San Miguel de cada año, celebrarían un aniversario solemne por el dicho obispo. Y que ese día se daría al convento pitanza general"s.

La donación fue confirmada, a petición del monasterio, por el Papa Alejandro IV, que dio una bula en Anagni en los idus de junio de 1260 que es el 11 de junio, en el sexto año de su pontificado9. Tal y como consta en el Lumen Domus Petrae, "el Monasterio por espacio de muchos años nombró en vicario de dicha iglesia de Llumes a diferentes personas seculares y regulares" 10 , es decir, sacerdotes ordenados miembros del clero secular o religiosos del propio monasterio. Ejerció este derecho hasta 1624 .

De los documentos de la donación se deduce que la iglesia y la población ya existían cuando Piedra las recibió. En efecto, el templo, situado a $9 \mathrm{~km}$. de la abadía, es una interesante iglesia románica de la segunda mitad del siglo XII o de inicios del XIII. Jesús Andrés Navarro mantiene la cronología de inicios del s. XIII y relaciona formalmente el edificio con las ermitas románicas de Guadalajara ${ }^{11}$. Construida en buena piedra, escuadrada sólo en los esquinazos del muro, en las puertas,

7 A. H. N., Lumen Domus Petrae, Cód. 55-B, fol. 1500.

8 Ibidem, fol. 1281. La aceptación de la donación dice: "Nos praedicti Abbas et conventus, vobis Reverendo Patri Domino Episcopo memorato, devote, et spirituali retributione, grata volentes vicissitudine respondere; ad quotidianam orationem, seu commenorationem faciendam, et unam lampadam tenendam, quo die noctuque ardeat coram altari Virginis Gloriosa pro vobis, in Monasterio nostro perpetuo; necnom ad aniversarium in die Sancti Michaelis, annis singulis in praedicto Monasterio in perpetuum, pro Vobis solemniter faciendo; et ipsa die ratione ipsius aniversarii, preadicto conventui parandam pitantiam generalem; vobis, ac sucesoribus vestris, et ecclesia tirasonensi, ratione huius donationis, nos et Monasterium nostrum per presentem paginam in perpetuum obligamus". A. H. N., Lumen Domus Petrae, Cód. 55-B, fol. 1282-1283.

9 "Alexander episcopus servus servorum Dei. Dilectis filiis abatti et conventui Monasterii de Petra, cisterciensis ordinis, tirasonensis diócesis, salutem et apostólicam benedictionem. Devotionis vestro sinceritas promeretur ut petitionibus vestris quantum cum Deo posumus favorabiliter annuamus. Cum itaque sicut petitio vestra nobis exhibita continebat, venerabilis frater noster tirasonensis episcopus ecclesiam de Flumes sua Diócesis, hunc vacantem, cuius collatio ad ipsum episcopum plene et libere pertinebat cum ómnibus juribus et pertinenciis suis, capituli sui ad hoc accedente consensu. Vobis in usus propios deputarit, reservata perpetuo vicario servituro in ea congrua de ipsius redditibus portione, pro ut in instrumento publico inde confecto plenius dicitur contineri. Nos vestris supplicationibus inclinati, quod super hoc ab eodem episcopo probide factum est ratum et gratum habentes, id auctoritate Apostolica confirmamus et prosentis scripti patrocinio communimus. Nulli ergo omnimo hominum liccat hanc pagimam nostrae confirmationis infringere, vel ei ausu temerario contraire. Si quis autem hoc attemptare praesumpserit, indignationem omnipotentis Dei et Beatorum Petri et Pauli Apostolorum, se noverit incursurum. Dattis Anagniae III dia Junii, pontificatus nostri anno VI”, A. H. N., Clero, Piedra, carp. 3674, doc. 9. Lumen Domus Petrae, Cód. 55-B, fol. 1284-1285. A. R. A. H., Colección de Manuscritos de Joaquín Traggia, Ms. B-138, fol. 159.

10 A. H. N., Lumen Domus Petrae, Cód. 55-B, fol. 1284-1285.

11 ANDRÉS NAVARRO, Jesús, "Llumes (Monterde)" en VV. AA. Coordinación científica de Javier Miguel, Enciclopedia del Románico en Aragón. Zaragoza, Aguilar de Campoo, vol. I, pp. 381-386. 
ventanas y fajones; usando sillarejo mampuesto de cal hidráulica en los muros. En planta se ajusta al modelo arquitectónico de iglesia ermita ${ }^{12}$, tiene una única nave de apariencia rectangular, de 21,30 m. de longitud, 5,20 m. de anchura en el ábside y $5,70 \mathrm{~m}$. en el presbiterio, cubierta con bóveda de medio cañón, dividida en cuatro tramos con la ayuda de 3 arcos fajones más bien rebajados que esbeltos y coronada en la parte oriental con un ábside semicircular al interior y al exterior que se cubre con bóveda de horno de buen trazado (fig. 1). Todos los canecillos exteriores son lisos. El arco de triunfo que separa el presbiterio de la nave es el más destacado,

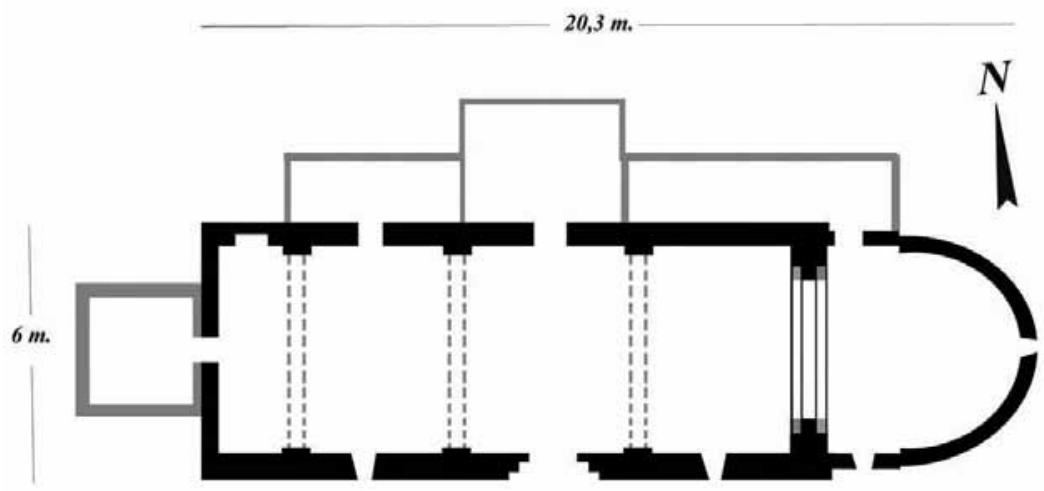

Aproximación a Ia planta de la iglesia de Llumes A. Garcia Omedes

Fig. 1. Iglesia de San Miguel de Llumes, segunda mitad del s. XII- inicios del s. XIII, planimetría según A. García Omedes.

tiene forma de leve herradura, $3,25 \mathrm{~m}$. de amplitud, se ajusta al tipo doblado o con un único acodamiento de arquivolta, y se asienta en sendos pilares con medias columnas en los frentes, basamento ático, esquinas rematadas en baquetón y capiteles historiados que han conservado parcialmente sus relieves, agrupando tres capiteles a cada lado (fig. 2). El capitel de la izquierda, según lo observa el espectador, representa la huída a Egipto con la Virgen, montada en la mula, el Niño en el regazo (fig. 3) y San José con el hatillo al hombro, conduciendo la comitiva hacia una ciudad con la puerta cerrada que simboliza la entrada en el país del Nilo, todo ello con un fondo de palmeras y una sirena de cola bífida que se agarra con las manos los extremos de cada cola para mostrar abiertamente el sexo y simbolizar los cantos de sirena con que hechiza a los hombres y les conduce al pecado y la muerte. El capitel de la derecha tiene un relieve más difícil de interpretar. En él se reconoce a un ángel de alas explayadas saludando con la mano derecha abierta a la altura del pecho, que acaso sea San Miguel (fig. 4), y un obispo o abad mitrado con su báculo.

12 OLAGUER FELIÚ Y ALONSO, Fernando, El arte románico español, Madrid, Encuentro, 2003. 


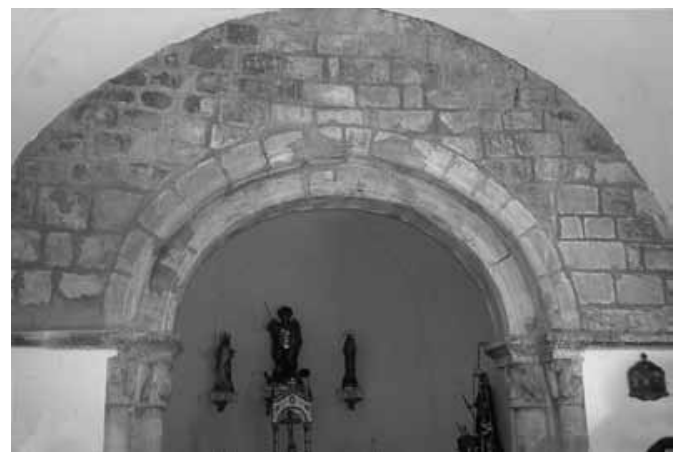

Fig. 2. Iglesia de San Miguel de Llumes, arco de triunfo, s. XII-XIII.

(los cuadrupedos simétricos) y la liberación del alma (las aves que vuelan) mal (los cuadrúpedos simétricos) y la liberación del alma (las aves que vuelan) ${ }^{13}$. Los cimacios sobre los capiteles están decorados con estrellas de seis puntas dentro de hexágonos. Los relieves vegetales que componen los frisos recuerdan mucho a los trabajos de la eboraria. Desde el punto de vista estilístico las representaciones antropomorfas son figuras mofletudas, de caras redondeadas, con cuidadoso tratamiento de paños y temas vegetales con dígitos dentados.

La única puerta de acceso a la iglesia está abierta en el muro sur, mide 3,06 m. de ancho y tiene una luz de 1,42 $\mathrm{m}$. Es un sencillo arco de medio punto doblado (fig. 5) con columnas acodilladas de basamento ático, fuste liso y capitel historiado con monstruos simétricos enfrentados: cuadrúpedos y sirenas pájaro con cabeza femenina y fondo estrellado con luna en cuarto creciente. Las arquivoltas no recibieron ninguna clase de decoración. Lo más sobresaliente de la portada es el tímpano monolítico sostenido sobre dos ménsulas decoradas con caras femeninas muy machacadas. Una representa a una mujer con el pelo suelto mientras que la otra es una mujer con toca de tela cubriéndole el cabello. En la parte superior de ambas cabezas se han conservado restos de policromía en rojo y azul. Desde el punto de vista iconográfico podrían simbolizar la mujer soltera y casada o acaso la alegoría
Alrededor de ellos hay símbolos vegetales y animales enfrentados simétricos, cuadrúpedos y aves. No es fácil dar una lectura iconográfica a este capitel, puede ser una representación de la ceremonia de consagración del edificio en la que el obispo de Tarazona o el abad mitrado de Piedra consagraron la iglesia a la devoción a San Miguel Arcángel y al participar en la ceremonia se produce la floración del alma de los fieles que entran en contacto con Dios (temas vegetales) y el enfrentamiento en psicomaquia del bien y el

. 
de la sinagoga y la iglesia. En la superficie del tímpano se representó un Pantócrator rodeado por el tetramorfos. Cristo está dentro de la almendra mística, entronizado, con escabel a los pies, bendice con la mano derecha y lleva el libro de la ley en la izquierda. A ambos lados está el tetramorfos alado, por medio de los símbolos de los cuatro evangelistas perfectamente adaptados al marco arquitectónico. A la derecha de Cristo está San Mateo, representado como un án-

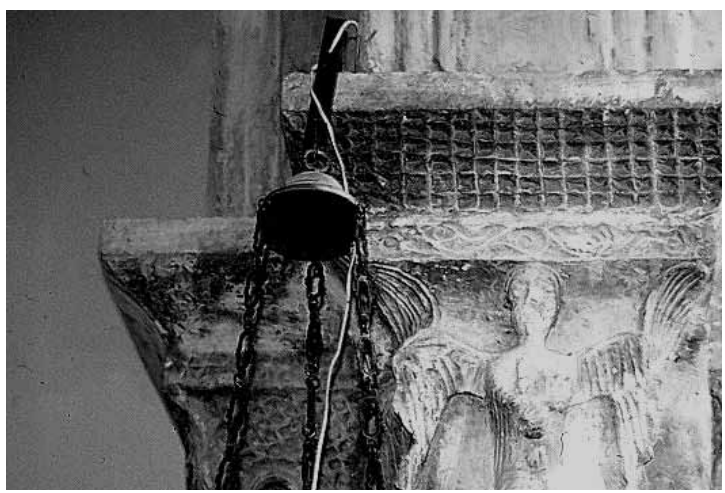

Fig. 4. Iglesia de San Miguel de Llumes, capitel de San Miguel Arcángel situado en el arco de triunfo, s. XIII. gel genuflexo, bajo él San Marcos como un león alado con la cabeza vuelta. A la izquierda está el águila de San Juan y el toro de San Lucas en posición simétrica a la de San Marcos, es decir, el buey alado con la cabeza vuelta. La composición general muestra relación directa con el deteriorado tímpano de la Iglesia de San Miguel de Daroca. Los violentos giros del cuello dan a estas esculturas una cronología tardía dentro del primer cuarto del siglo XIII ${ }^{14}$. Sin embargo, lo más singular de este tímpano se encuentra dentro de la almendra mística ya que a la izquierda de Cristo está representado un Crismón trinitario de modelo jaqués, con 6 brazos, que constituye una auténtica manifestatio trinitatis a la manera de un signo de bienvenida. La originalidad radica en estar situado el crismón dentro de la almendra y, en consecuencia, puede relacionarse con algunos tímpanos como el de San Miguel de Estella ${ }^{15}$. El Crismón Trinitario, como es de todos bien sabido, muestra a Dios Padre por medio de la letra $P$, al Hijo por medio del Crismón $X P$ y al Espíritu Santo por medio de la $S$ y sobrepone los tres símbolos dentro de una rueda de la que cuelgan las letras $A$ y $W$ que simboliza la atemporalidad de Dios, es decir, la verdad eterna que no tiene principio ni fin ${ }^{16}$. El Crismón Trinitario que aparece en el tímpano de Llumes es uno de los más meridionales de Aragón. Seguramente es copia de alguno de los crismones presentes en

14 ANDRÉS NAVARRO, Jesús (2010), op. cit., p. 386.

15 MARTÍNEZ DE AGUIRRE, Javier Miguel, "La portada de San Miguel de Estella. Estudio iconológico" en Príncipe de Viana, Año 45, n 173, 1984, pp. 439-462.

16 CAAMAÑO MARTÍNEZ, Jesús, "En torno al tímpano de Jaca” en Goya, n 142, 1977-1978, p. 207; ÍNIIGUEZ-ALMECH, Francisco y SÁNCHEZ VENTURA, R., La Catedral de Jaca y los orígenes del románico Español, Jaca, 1967; OCÓN ALONSO, Dulce, "Problemática del crismón trinitario" en Archivo Español de Arte, 1983, n 223, pp. 242 y ss.; OCÓN ALONSO, Dulce y RODRÍGUEZ ESCUDERO, P., "Los tímpanos de Jaca y Santa Cruz de la Serós, una pretendida relación modelo-copia" en Actas del V Congreso Español de Historia del Arte, Barcelona, 1984, t. I, pp. 259 y ss.; OLAGUER FELIÚ Y ALONSO, Fernando (2003), op. cit., pp. 94-101. 


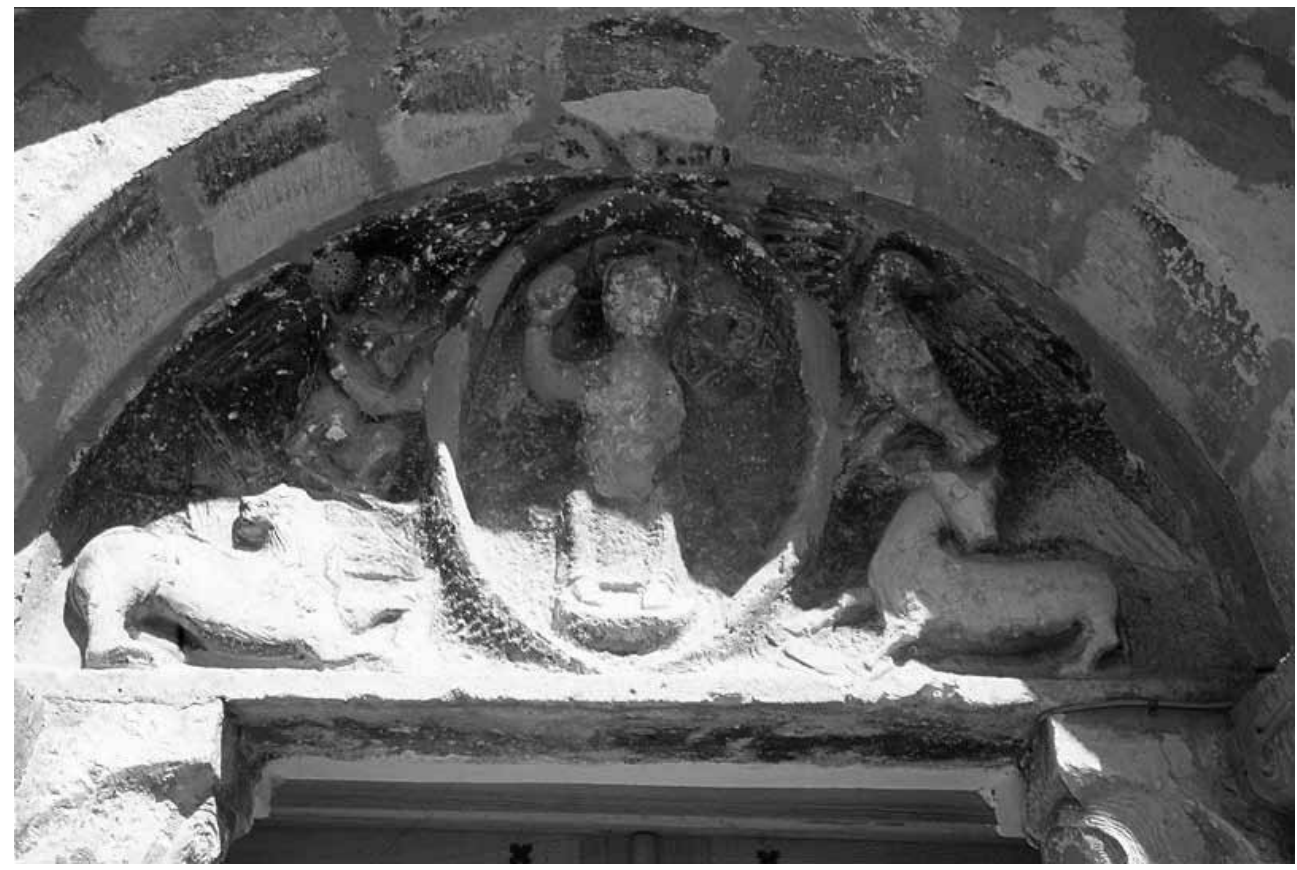

Fig. 5. Iglesia de San Miguel de Llumes, portada meridional, detalle del tímpano con pantócrator y crismón trinitario, s. XIII.

los pergaminos del Monasterio de Piedra ${ }^{17} \mathrm{o}$ acaso copia el crismón labrado sobre la puerta que da acceso a la iglesia abacial de Piedra. La calidad escultórica de los relieves de Llumes es muy desigual. Deberíamos admitir al menos dos manos, una más elaborada, que ha visto trabajos de eboraria y los imita, que labra los capiteles del interior de la iglesia y a quien se pueden atribuir obras de estilo análogo en el contorno, como lo es la puerta meridional de la iglesia de la Presentación de Cimballa. Hay un segundo maestro que es un artista más popular y rudo, responsable de los relieves de la portada.

La documentación medieval sobre Llumes es muy variada. El 15 de febrero de 1280 Rodrigo Abad, vicario de la iglesia de Llumes, su hermana, India, y su sobrino, Fernando, permutaron con Martín Pérez, abad de Piedra, una pieza de tierra situada en el congosto de Cocos, en el término de Carenas, a cambio de tres fincas en Llumes ${ }^{18}$. En Piedra, a 13 de las calendas de noviembre de la Era de 1342, que es el año 1304, ante el notario Domingo Bueno: "el monasterio, en fuerza de la donación de la Iglesia y décimas de Llumes, percibía las décimas del territorio de dicho lugar. Y porque tenía en él algunas heredades y el cuarto de las décimas

\footnotetext{
17 A. H. N., Clero, Piedra, carp. 3663, doc. 6 y 3664, doc. 16.

18 A. H. N., Clero, Piedra, carp. 3679, doc. 10.
} 
se sacaba del granero para el sustento de la Iglesia, se ajustó con el concejo de dicho lugar, por razón del cuarto de sus heredades que le daría de renta en cada un año 8 fanegas de trigo y 3 de centeno; y que con esto no pudiesen pedirle otra cosa. Hizo el monasterio la dicha obligación y el concejo la aceptó, prometiendo no pedir otro ni más" $" 19$.

Pese a la claridad de ambas donaciones (episcopal y pontificia) la vicaría de Llumes dio no pocos quebraderos de cabeza al Monasterio de Piedra. En 1382 figura entre las posesiones del monasterio en el "Libro del Chantre" que recoge las propiedades episcopales de la diócesis de Tarazona ${ }^{20}$. Sin embargo, el concejo de Monterde entabló un pleito para hacerse con la parroquia de Llumes, que no llegó a prosperar. La relación tensa de Piedra con Llumes y Monterde era muy antigua. En escritura firmada ante el notario Ximen Pérez, el 27 de junio de 1384 consta: "el concejo de Llumes vendió al monasterio las 8 fanegas de trigo y 3 de centeno que le pagaba en cada un año por razón del quarto o quartadécima de las heredades que poseía en el territorio de dicho lugar; y también 9 sueldos de renta que daba al dicho concejo por el vino que bebían los vecinos, cuando diezmaban sus panes; y todo esto por precio de 410 sueldos, con cuya cantidad redimió el monasterio los cargos" ${ }^{21}$.

En 1414 consta documentalmente que Llumes era aldea de la comunidad de Calatayud, en cuyo monedaje de aquel año figura la cifra de 8 maravedíes frente a los 29 de Monterde $^{22}$. En 1454, en ocasión de la guerra de Juan II de Castilla contra Alfonso V de Aragón, que fue en esencia un conflicto fronterizo, quedaron destruidos los lugares de Llumes, Somed, Cocos, Horcajo y Manubles. No conocemos la fecha exacta de despoblamiento de Llumes, pero, cuando se deshabitó por completo, a finales del siglo $\mathrm{XV}$, los vecinos que quedaban vivos debieron pasar a Monterde y se decidió, en la cláusula 36 de la concordia que se firmó el 2 de enero de 1475 ante los notarios Pascual Luzón de Carenas y Domingo Pérez de Abanto que, desde ese momento y por el tiempo en que Llumes estuviese despoblado: "el concejo de Monterde, hubiese de señalar una persona que en compañía del vicario de la Iglesia de Llumes tuviesen cuidado de los reparos y cosas necesarias de dicha Iglesia; convirtiendo y gastando en esto el cuarto y primicia pertenecientes a dicho lugar" ${ }^{23}$. Queda claro en la concordia que Piedra hubo de ceder los derechos señoriales que tenía sobre la iglesia parroquial de Llumes a favor de la parroquial de Monterde, a la que quedaron adscritos los pocos habitantes que habían sobrevi-

19 A. H. N., Lumen Domus Petrae, Cód. 55-B, fol. 1286

${ }^{20}$ CORRAL LAFUENTE, José Luis, "El obispado de Tarazona en el siglo XIV: el libro del Chantre: II. Las propiedades episcopales" en Turiaso, II, Tarazona, 1981, p. 220.

21 A. H. N., Lumen Domus Petrae, Cód. 55-B, fol. 1286.

22 UBIETO ARTETA, Antonio, Los pueblos y los despoblados, Zaragoza, t. I, 1984, t. II, 1985, pp. 810 , 884-885.

${ }^{23}$ A. H. N., Lumen Domus Petrae, Cód. 55-B, fol. 1220. 
vido. El pueblo debió abandonarse pero la iglesia de San Miguel, que seguía siendo propiedad de los monjes de Piedra, debía mantenerse en pie y con culto. Las tierras de Llumes pasaron a ser explotadas por los vecinos de Monterde en calidad de quiñoneros. La iglesia de Monterde se benefició del cobro del diezmo y primicias de Llumes, pero, en compensación, debía dar a Piedra una parte de este producto. La cantidad fijada fue siempre la manzana de la discordia. Los de Monterde decían emplearla en el mantenimiento de la iglesia de Llumes y los de Piedra siempre reclamaron las cantidades que les correspondían. Finalmente: "el dicho concejo de Monterde renunció a favor del Monasterio el derecho y pretensión que tenía acerca de este patronato, con que se acabó esta cuestión y el Monasterio quedó con este derecho claro y en práctica" 24 .

En documento fechado en Calatayud, el 24 de septiembre de 1484 consta que, ante Berengario Martínez de Daroca, prior de la colegiata de Santa María de la Peña y vicario general de Calatayud, por nombramiento episcopal de Tarazona, compareció Pedro Tris, notario de las causas de la ciudad y procurador de Piedra, que, como patrono de la iglesia de Llumes, presentó a Martín de Luna como aspirante a la vicaría vacante de Llumes. Tras haber presentado los documentos en virtud de los cuales los monjes afirmaban su derecho, presentó el procurador una serie de testigos el 23 de marzo de 1384 y, ese mismo día, presentó un documento fechado el 15 de marzo de 1459 en el que el obispo Gregorio de Tarazona ponía al Monasterio de Piedra en posesión de la vicaría de Llumes. En el documento se revela que el cargo de vicario de Llumes había estado siempre servido por un monje de Piedra. El vicario general, ante tantos documentos probatorios, hubo de admitir al candidato propuesto y le concedió la colación canónica el 24 de septiembre de $1484^{25}$. Fray Martín de Luna nos consta como cillerero de Piedra entre 1484 y $1489^{26}$.

Según el Lumen Domus Petrae: "El licenciado Gil Ximeno, clérigo de esta diócesis de Tarazona, residente en Roma, movió pleito a este monasterio sobre la vicaría de Llumes, en tiempo del pontifice Alejandro $6^{0}$, el cual dio comisión a su auditor Achiles de Grafsis, para el conocimiento y decisión de la dicha causa. Y el dicho auditor concedió letras citatorias contra este Monasterio y dio comisión al doctor García Forcén, canónigo limosnero de Santa María de Calatayud, para que hiciese sacar transumpto fe faciente de las escrituras y documentos concernientes al derecho que el Monasterio pretendía tener a la vicaría de Llumes y también para que en esta diócesis se hiciese información de la costumbre y estilo que había de proveer, regir y administrar la vicaría de Llumes. Y el dicho Doctor García Forcen, requerido por parte del Monasterio, mandó copiar la donación de la iglesia de

\footnotetext{
24 Ibidem, fol. 1487.

25 A. H. N., Clero, Piedra, carp. 3736, doc. 1.

26 A. H. N., Clero, Piedra, carp. 3735, doc. 16; 3738, doc. 17.
} 
Llumes y la confirmación apostólica [...] juntamente con las colaciones de dicha vicaría dadas a los vicarios presentados por parte del Monasterio. Y así mismo se hizo información y depusieron muchos testigos, que el último estado de la dicha vicaría era haberse regido y administrado por espacio de más de cincuenta años, por religiosos de este Monasterio de Piedra, a quienes la dicha vicaría se había conferido, presentándolos el convento y dándoles la colación el obispo de Tarazona o sus vicarios generales" 27 . Se hicieron tres cuadernos para remitirlos a Roma, signados por los notarios bilbilitanos Pedro Calvo y Pedro Díaz, pero no se llegaron a enviar porque la causa quedó suspensa.

A los siglos XIII, XIV y XV corresponden en la iglesia de Llumes varias obras rotundamente indocumentadas. La primera de ellas es una batería de tres capillas yuxtapuestas al muro norte. Todas son pequeñas, tienen planta cuadrada y se cubren con bóveda de cañón apuntado, lo que parece indicar su cronología dentro del siglo XIII. Debieron ser capillas funerarias aunque se ignora quiénes se hicieron enterrar allí. Al siglo XV corresponde un bello púlpito mudéjar de yeso tallado que desarrolla lazo de estrellas de ocho puntas caladas y cruces griegas de punta afilada (fig. 6).

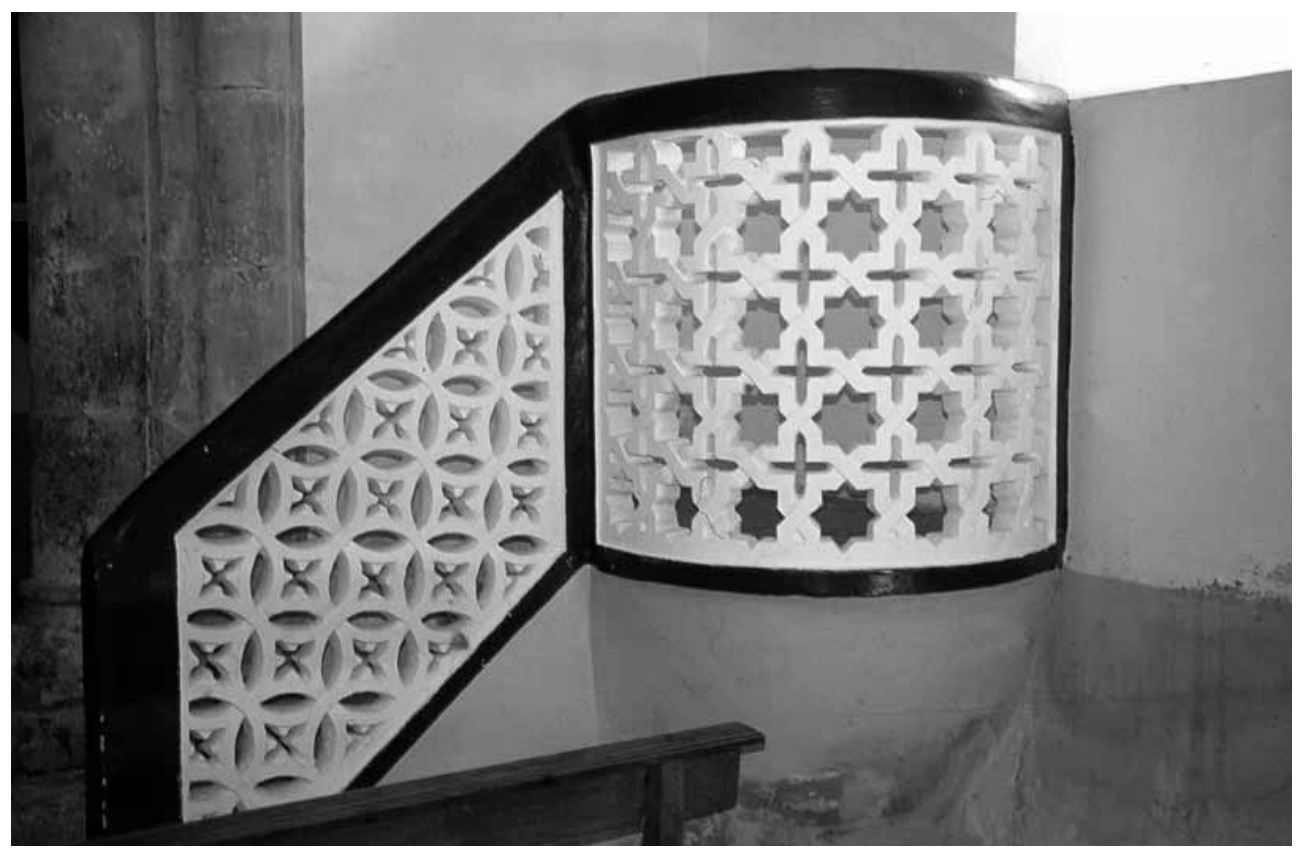

Fig. 6. Iglesia de San Miguel de Llumes, púlpito mudéjar de yeso calado, s. XV.

27 A. H. N., Lumen Domus Petrae, Cód. 55-B, fol. 1286-1287. 
Más sorprendente resulta encontrar un fraile fugitivo y excomulgado. El 14 de enero de 1504, ante el notario real Pedro Calvo: "García Gil del Portillo, abad de Piedra, con atendencia de que Fray Pedro Pérez, monje profeso del dicho monasterio y vicario de Santa María de Llumes habia hecho fuga y, no aparecido en espacio de dos años, llevándose algunos bienes del mismo monasterio, de que había constado legítimamente al dicho abad, asi por la notoriedad como por información que hizo para ello. Declaró que el dicho fugitivo había incurrido en las penas de tal y en la excomunión que se publica en la orden el Domingo de Ramos y lo privó de la dicha vicaría" ${ }^{28}$. Las razones por las que Pedro Pérez huyó nos son ignotas, "pero después se movieron acerca de esto algunas diferencias entre el monasterio y el capítulo eclesiástico de Monterde y mediante una concordia, cedió el monasterio la dicha vicaría de Llumes a favor de dicho capitulo de Monterde con ciertas reservas, pactos y condiciones, y quedando exemptas de pagar décima y primicia todas las piezas y heredades que tuviese el monasterio en la pardina de Llumes, aunque se cultivasen por mano ajena y por vecinos de Monterde: Se obligó el capitulo de la Iglesia de dicho lugar a pagar a este monasterio en cada un año 35 sueldos jaqueses de cargo ordinario y renta perpetua el día 20 de diciembre, con lo cual el dicho capítulo es dueño de la vicaría. Pero si en algún tiempo se poblase el lugar antiguo de Llumes, o el monasterio hiciese nuevo lugar y pusiese vecinos en Val de Nogueras, volvería la dicha vicaría de Llumes a poder del monasterio "29. El patronato de la vicaría de Llumes se mantuvo hasta 1614, fecha en que fue cedido definitivamente al capítulo de Moterde ${ }^{30}$.

Conocemos bien las condiciones en que se hizo la cesión: "Estando vacante la vicaría de Llumes, presentó este monasterio para vicario de ella al Padre Fray Sebastián de Cisneros, monje de este Monasterio. Y el concejo de Monterde pretendió que por tener unida a su territorio la Pardina de Llumes, estando despoblado el dicho lugar, le pertenecía el derecho de presentar, por los derechos que tienen los lugares de este arcedianato, para que los hijos de cada parroquia obtengan y sirvan los beneficios y curatos de ella, y que estando subrogado el lugar de Monterde en los derechos que pertenecian al de Llumes, los hijos de Monterde habian de gozar del favor concedido a los de Llumes entre tanto que éste estuviese despoblado. $Y$ con este motivo presentó el dicho concejo para vicario de Llumes al licenciado Jaime Andrés, presbitero, con la calidad de ser hijo de Monterde y descendiente de un vecino del lugar de Llumes, que lo fue en tiempo que había población. Ventilóse esta causa ante el Vicario General de este arcedianato de Calatayud, y después de concluida, en un proceso que se intitulaba Procesus Praesentationis vicariae ecclesiae de Llumes facte de Persona Sebastián de Cisneros Monachi de Petra. Los procuradores de las partes pidieron sentencia ante el Doctor Don Miguel de

\footnotetext{
28 Ibidem, fol. 85.

29 Ibidem, fol. 1487-1488.

30 A. H. N., Clero, legajo 8525.
} 
Ortiz, arcediano de Tarazona, oficial eclesiástico y Vicario General de la ciudad de Calatayud y su arcedianato, el cual por su sentencia admitió la presentación hecha por el Monasterio de la persona del padre Sebastián de Cisneros, declarando que sólo al convento tocaba el derecho de presentar y repelió la presentación hecha por el concejo de Monterde"'31. Sebastián de Cinseros fue el LIV abad de Piedra entre 1606 y 1609 . La sentencia se data el 1 de febrero de 1614 y el concejo de Monterde apeló a Su Santidad y al arzobispo metropolitano de Zaragoza, pese a lo cual, la colación de la iglesia de Llumes fue confirmada a favor de Fray Sebastián de Cisneros en documento dado por Marco Antonio de la Justicia, notario del número de Calatayud y regente de la escribanía de su oficiliado32.

Después de todos los enfrentamientos por el patronato de la vicaría de Llumes, en Monterde, el 29 de septiembre de 1614, ante el notario Antonio Rubio Ximeno, domiciliado en el citado pueblo, el concejo de Monterde convino con el Monasterio de Piedra renunciando al posible derecho que le podía corresponder: "y el Monasterio, por razón de los gastos que el dicho concejo habia hecho en el pleito, le hizo donación de 29 cahíces de trigo, 17 cahíces y medio de centeno y 1 cahiz y una anegada de cebada, y 8 cahíces de avena, todo lo cual otorgó el dicho concejo haber recibido en su poder. Y prometió en lo venidero por sí y por los singulares vecinos de dicho lugar que no pondría pleito, ni lo seguiría en orden a la dicha vicaría. Y que si tal pleito intentase dicho concejo o algún vecino de dicho lugar, restituirían al dicho monasterio los dichos granos que el convento les había dado. A lo cual obligaron sus personas y bienes "33. A partir de esta fecha el capítulo eclesiástico y la iglesia parroquial de Monterde estaban obligados a pagar a Piedra la cantidad de 35 libras anuales por los derechos decimales de la antigua vicaría de Llumes ${ }^{34}$. Fue entonces cuando debió construirse la torre de la iglesia de San Miguel. Su planta inferior sirve de baptisterio y su escalera lo mismo sirve para subir a la tribuna que al cuerpo de campanas. Que la torre de Llumes tenga sólo unas pequeñas ventanas cuadradas se debe a que no tenía vecinos y no eran necesarios grandes arcos de medio punto para colgar las campanas y convocar a misa.

En Calatayud, a 20 de noviembre de 1636: "el Vicario General de este Arcedianado de Calatayud, despachó letras de excomunión y monitoria general contra todas las personas residentes en este Arcedianado, para que manifestasen qualesquiere escrituras, protocolos y papeles concernientes a la vicaría de Llumes, y los que tocasen a otros bienes y derechos pertenecientes al Monasterio de Piedra" 35 . Tales letras fueron comunicadas a la parroquial de Monterde el 5 de diciembre de ese mismo año.

\footnotetext{
31 A. H. N., Lumen Domus Petrae, Cód. 55-B, fol. 1288.

32 Ibidem, fol. 1289.

33 Ibidem, fol. 1290

34 A. H. N., Clero, libro 18660.

35 A. H. N., Lumen Domus Petrae, Cód. 55-B, fol. 1480.
} 
En 1642 se documenta uno de los pocos pleitos que se sentenciaron en contra del Monasterio de Piedra ${ }^{36}$. Nuevamente se enfrentaban la abadía y el capítulo eclesiástico de Monterde por el nombramiento de la vicaría de Llumes. En virtud de la nueva sentencia, el cabildo de Monterde pasó a nombrar al vicario de Llumes y tal derecho le fue retirado al abad de Piedra. Según consta en el Lumen Domus Petrae: "estando vacante la vicaría de Llumes por muerte del Padre Simón García, último vicario, presentó este Monasterio para vicario al Padre Fray Pedro Cortés. A la cual presentación se opuso el licenciado Juan Marco de Lequena, natural de Monterde; y sobre ello pendió pleito ante el Vicario General de Calatayud. Y estando pendiente, comprometieron estas diferencias el Monasterio y el capitulo eclesiástico de Monterde, nombrando en árbitros al licenciado Gaspar Cortés, racionero de la Iglesia de San Miguel de Daroca y al licenciado Pedro Marco Salido, vicario de Monterde" ${ }^{37}$. La sentencia arbitral se pronunció en Munébrega, el 28 de octubre de 1642, ante los notarios bilbilitanos Iñigo Jerónimo de Carenas y Martín de Capilla, con decreto previamente dictado por el Vicario General de la Congregación Bernarda de Aragón, Dionisio Ferrer, que era abad de Rueda, el 24 de noviembre de $1641^{38}$. En la sentencia se establecían una serie de obligaciones del capítulo ecle-

36 BARBASTRO GIL, Luis, El Monasterio de Piedra. 1194-1836, Alicante, 2000, p. 48.

37 A. H. N., Lumen Domus Petrae, Cód. 55-B, fol. 1290.

${ }^{38}$ La sentencia fue muy clara: "Primeramente, declararon dichos árbitros que el dicho Padre Fray Pedro Cortés y el licenciado Juan Marco de Lequena, colitigantes y pretendientes de dicha vicaría de Llumes, se apartasen valida y eficazmente del proceso donde pendia su pretensión y los dichos árbitros los dieron por apartados". Con ello "adjudicaron la dicha vicaría de Llumes para siempre, con las rentas y emolumentos de ella al capítulo eclesiástico del lugar de Monterde". Impusieron las siguientes condiciones: "que el dicho capitulo desde luego y siempre que vacare la dicha vicaría, hubiese de presentar por vicario de Llumes a uno de los beneficiarios capitulares del dicho capitulo que actualmente sirvan en él. Y que el presentado con sólo el acto de su nombramiento pueda obtener la colación de dicha vicaría. [...] Adjudicaron al dicho capitulo de Monterde todas las décimas, primicias, obligaciones y emolumentos que hasta entonces habian tocado al Monasterio por razón de la dicha vicaria, y le dieron derecho de percibirlas en lo venidero. [...] Mandaron que el convento renunciase a favor del dicho capitulo de Monterde, todos los derechos que tenía y le pertenecían para presentar vicario de la iglesia de Llumes y para percibir y cobrar las décimas, primicias, oblaciones y otros emolumentos anexos a la dicha vicaría, en y a favor del dicho capitulo de Monterde; y los dichos árbitros le dieron por renunciado". También "declararon que todas las heredades y piezas que el monasterio poseía en las vegas y pardina de Llumes, asi las que llamaban piezas de la vicaría, como otras cualesquiere que el monasterio poseía hasta entonces por cualesquier título, hubiesen de gozar perpetuamente de la exempción de pagar décima ni primicia de cualesquier granos y frutos que se cogiesen en ellas, así cultivándolas el Monasterio, o a sus expensas, como arrendándolas o dándolas a treudo, y de cualesquier otra manera que se cultivasen. Y que con la misma exempción las pudiese vender a cualesquier persona. [...] declararon que si desde el otorgamiento de esta sentencia en adelante, comprare el Monasterio algunas heredades en la pardina de Llumes, dos personas puestas una por el convento y otra por dicho capitulo de Monterde, dentro de cuatro días después de la compra, hayan de computar y hacer juicio de lo que importara en cada un año la décima y primicia de lo que fructaren dichas heredades compradas, reduciéndolas a dineros. $Y$ lo que juzgaren que suma la dicha décima y primicia, se haya de descontar de los dichos 700 sueldos de renta en que se obliga al dicho capitulo de Monterde, que pague en cada un año al dicho monasterio. Y si dichas dos personas no se conformasen en la dicha tasación, el convento y el dicho capitulo hayan de nombrar un tercero, otros cuatro días, después que las dos personas no se hayan conformado; y el dicho tercero, haya de hacer la dicha tasación en la forma dicha. Y mandaron que las dichas tasaciones, cada una en su caso, la hayan de hacer dichas personas por todo el mes de octubre de aquel año en que el convento había comprado 
siástico de Monterde con la iglesia de Llumes, algunas de las cuales tienen implicaciones artísticas evidentes: "mandaron que el dicho capitulo de Monterde tuviese cargo y obligación (por razón de las décimas, primicias y otros emolumentos que habia de percibir como vicario de la dicha vicaría de Llumes de reedificar y reparar siempre que fuere necesario la iglesia de dicho lugar de Llumes y proveerla de ornamentos, así para decir misa como para la decencia de los altares, y cumplir con las obligaciones y cargos de dicha vicaría, como son decir misa en dicha iglesia todos los domingos y fiestas calendas del año. Y que hubiesen de pagar los cargos y obligaciones anexos a dicha vicaría, asi los que se debian hasta entonces, como los que en adelante se debiesen a cualesquier personas, sacando indemne de todo ello al monasterio y de las costas. [...] Declararon que el religioso granjero que por tiempo fuese de Llumes pudiese tener una llave de la puerta de la iglesia de dicha pardina, para entrar a decir misa, hacer oración, y lo demás que le pareciese francamente" 39 . Ese mismo año de 1642, el capítulo de Monterde se dirigió al Vicario General del Arcediano de Calatayud, Miguel Iván Martínez, pidiendo exonerase al capítulo del cargo de presentar vicario para Llumes por no haber lugar poblado $\mathrm{y}$, en consecuencia, no haber vecinos a los que administrar los sacramentos y evitar así los gastos de colación, a lo que "condescendió dicho Vicario General como visitador del Arcediano relevando y extinguiendo por su formal decreto dicha vicaría de Llumes y exceptuando el caso de nueva población de Llumes o Valdenogueras, y obligando a dicho capitulo a celebrar las misas acostumbradas en Llumes y demás

alguna de dichas heredades. Con esto empero que por no hacerse o dilatarse dichas tasaciones, no se pueda retardar la paga del cargo de los dichos 700 sueldos que el capítulo de Monterde deberá pagar en cada un año al Monasterio. Y se reserva al dicho capítulo la acción de repetir y cobrar del convento lo que sumaren dichas tasaciones cuando aquellas se hagan. Y que en adelante se desfalque y descuente aquello del dicho cargo y pensión. [...] Declararon que si el dicho convento comprare en lo venidero tantas heredades de nuevo en la dicha Pardina de Llumes, que la décima y primicia de los frutos de aquellas importaren la cantidad de 700 sueldos en cada un año, en ese caso el dicho capitulo de Monterde, quedara sin obligación de pagar al Monasterio el dicho cargo y obligación de los 700 sueldos. Y desde entonces en adelante, todas las heredades que el dicho convento comprare en la dicha Pardina de Llumes hayan de gozar y gocen de la inmunidad y libertad de no pagar décima ni primicia de los frutos de aquellas al dicho capítulo de Monterde ni a la Iglesia de Llumes, ni a otro puesto ni persona.[...] Condenaron al dicho capítulo eclesiástico de Monterde que haya de pagar en cada un año al dicho Monasterio de Piedra por la cesión y renuncia de la vicaría de la Iglesia de Llumes, y de las rentas y emolumentos de ella, que de parte de arriba se ha hecho a favor suyo, la cantidad de 700 sueldos jaqueses de pensión y cargo, el día 20 de diciembre de cada un año, comenzando la primera paga el dicho día del año 1643; Y así de allí adelante en semejante día perpetuamente, llevando la dicha cantidad al Monasterio a sus expensas y entregándola al señor Abad o cillerero de dicho convento. [...] Condenaron al dicho capítulo de Moneterde a que el día de la prelación de esta sentencia diese y pagase al Monasterio por una vez tan solamente 2280 sueldos jaqueses en dinero contado, sin que por esto el Monasterio quedase obligado a darle ninguna satisfacción. [...] Declararon que si en el tiempo venidero el Monasterio poblase o hiciese lugar en la partida llamada Val de Nogueras, o si poblase el lugar de Llumes, y con dichas poblaciones el dicho convento o los nuevos pobladores de dichos lugares fueren señores de la Pardina de Llumes, en dichos casos y cualesquiera de ellos, esta sentencia y todo lo en ella contenido, hayan de quedar extintas, nulas y de ningún efecto ni valor, más que si no se hubiese otorgado”. A. H. N., Lumen Domus Petrae, Cód. 55-B, fol. 1292-1294.

39 Ibidem, fol. 1291-1292. 


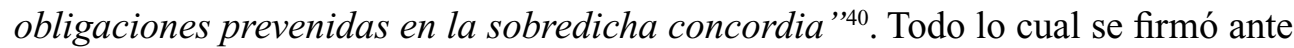
el notario bilbilitano Jorge Iñigo de Zárate, secretario de la visita.

No menos interés tiene el hecho de que las tierras de Llumes, en ocasión de haberse firmado la concordia que poblaba Villanueva de Piedra, en 1649, fueron dadas a los nuevos pobladores ${ }^{41}$, de donde se deduce que, excepto las que dependían del granjero, las demás estaban sin arrendador.

En 1790 tenemos los nombres de los 10 mayores contribuyentes que daban tributo a Piedra según consta en el Archivo Historico Nacional ${ }^{42}$ y según recoge Barbastro Gil ${ }^{43}$. Tales contribuyentes, pagaban el diezmo y colecta de Llumes y eran: Juan Pardos, mesonero, esquilador, hortelano y arrendador de tierras, que pagaba a la abadía 47 sueldos anuales. Vicente Mogollón, molinero, que pagaba 4 sueldos. Félix Blancas, administrador de la capellanía y beneficio que gozaba en la parroquial de Monterde que pagaba 36 sueldos. Vicente Arregui, cubero, que pagaba 32 sueldos. Vicente Villa, tendero, que pagaba 31 sueldos, José Gonzalo, podador y propietario de tierras, que pagaba 30 sueldos. Antonio Llorente, alpargaterro y arrendador de las tierras dependientes de la capellanía, que pagaba 26 sueldos. Mamés Ruíz, pastor que pagaba 26 sueldos. José Bueno, colector del diezmo, que pagaba 25 sueldos. Una parte de estas cantidades iba a las arcas generales del Monasterio de Piedra y otra parte servía para atender al beneficiado de la parroquial. En fecha incierta entre 1643 y 1790, Llumes volvió a repoblarse y Piedra recuperó el nombramiento de la vicaría de Llumes. El cobro del diezmo seguía siendo asunto conflictivo a finales del siglo XVIII, pues en 1799, se documenta un pleito que enfrentó a Piedra contra el concejo y clero de Monterde por el diezmo, sentenciado, una vez más, a favor de Piedra ${ }^{44}$.

Urzay Barrios ha aclarado por qué Piedra recuperó la vicaría de Llumes en 1790. "En el transcurso de la Edad Media, después de la conquista cristiana, Llumes y Monterde se constituyeron como dos aldeas pertenecientes a la comunidad de aldeas de Calatayud, independientes entre sí. En el siglo XIV Llumes se despobló completamente [...] esta fue la causa de su incorporación a Monterde. Sin embargo, el poderoso Monasterio de Piedra no estuvo conforme con la cesión y durante largos años mantuvo pleitos por la propiedad de este enclave abandonado. Hasta el siglo XVII no se dictó sentencia definitiva a favor de Monterde, si bien desconocemos bajo qué condiciones. Durante siglos nadie habitó en Llumes. Sabemos que hasta finales del siglo XVIII, era una pardina en el término de Monterde cultivada por sus agricultores, pero treudera al Monasterio de Piedra. El origen del Llumes

\footnotetext{
40 Ibidem, fol. 1295.

41 A. H. N., Cabreo sobre el lugar de Villanueva de Piedra, Cód. 183-B.

42 A. H. N., Clero, leg. 8525.

43 BARBASTRO GIL, Luis (2000) op. cit., p. 52.

44 Ibidem, p. 49.
} 
actual tiene un nombre propio: Juan Jaime Civera, infanzón residente en Ateca, cuya familia era oriunda de Magallón. Juan Jaime era ilustrado, hombre de negocios que desarrolló una gran actividad económica e intervino en las mejoras de las comunicaciones comarcales. Compró una finca de secano en Llumes que mejoró espectacularmente, con la ayuda de un hermano ingeniero. Por sus iniciativas empresariales y por su lealtad a la corona, recibió el título de Barón de Llumes en el año 1790. En medio de la finca adquirida, hizo construir una casa con oratorio, dependencias y viviendas para los obreros, todo alrededor de un patio central que servía como era para trillar. Mandó canalizar el río Piedra, construir acequias, puentes y caminos propios, allanar el terreno, en definitiva, organizar de forma racional un espacio de uso agrícola hasta entonces casi inservible. El resultado de tan magna obra, única en Aragón, puede verse todavía, pues sus descendientes han sabido conservar íntegra toda la estructura original de la finca. A lo largo del siglo XIX, Llumes fue la casa y las dependencias de la baronía. Sin embargo, la situación se modificó a principios del siglo XX. Una rama familiar de la baronía, por desavenencias internas, se instaló en una zona del pueblo llamada el barrio de oro, río arriba, junto al término llamado precisamente la pieza de oro. En el sitio llamado las Ermitas, que había sido abandonado siglos antes, junto a las ruinas de la vieja iglesia románica, un kilómetro más arriba del río Piedra, se instalaron a finales del XIX unas familias de Monterde, en torno a un molino harinero. Desde el alto del Royo se aprecia panorámicamente la disposición de los tres núcleos "45.

Madoz describe la granja de Llumes del siguiente modo "una espaciosa casa de campo con su oratorio, un palomar despoblado y una buena porción de terreno"46. La iglesia de San Miguel de Llumes, arruinada tras la desamortización, fue reconstruida en 1951 y autorizada como parroquia en 1953. Examinada en su conjunto es un edificio interesante porque, al ser una zona pobre y aislada, que apenas sufrió transformaciones en la Edad Moderna, posibilita un estudio integral del impacto que la arquitectura y la escultura del románico tardío y popular tuvieron en las primeras décadas del siglo XIII en las serranías situadas entre Daroca y el Monasterio de Piedra, en cuya jurisdicción administrativa debe estudiarse Llumes. Es, por tanto, un ejemplo del patrimonio rural poco conocido y muy digno de ser valorado $\mathrm{y}$ tenido en cuenta.

45 URZAY BARRIOS, José Ángel, Cultura popular de la comindad de Calatayud, Calatayud, Centro de estudios bilbilitanos, Institución Fernando el Católico, 2006, pp. 122-123.

46 MADOZ, Pascual, Diccionario Geográfico-Estadístico-Histórico de España, Madrid, La Ilustración, La Imprenta del Diccionario geográfico estadístico histórico, 1849. 